\title{
Intelligent polymer droplets eject membranes and drive multimodal-propulsion of floating objects
}

\author{
Pietro Ferraro $^{1}$, Sara Coppola ${ }^{1}$, and Veronica Vespini ${ }^{1}$ \\ ${ }^{1}$ Affiliation not available
}

May 10, 2021

\begin{abstract}
Self-propulsion of bodies floating in water is of great interest for developing new robotic and intelligent systems at different scales. Frequently, the propulsion concept has been related to the Marangoni effect often demonstrated through surfactants. Here we show for the first time that polymer droplets, made of appropriate combination of solvent/polymer, can represent a new strategy to activate different functionalities on water. We demonstrate that, by dispensing such intelligent polymer droplets, it is possible to propel motions with different modalities of any class of floating objects made of different shapes/materials. On demand propulsion and self-rotation (free and along a pivot) are reported for different objects. Furthermore, we discovered that meanwhile the object is propelled, polymer membranes can be created through the spreading phenomena on water's surface. Such thin polymer membranes can cover extensive areas and follow predefined paths as function on the motion assumed. We report preliminary example of possible exploitation of these new combined functionalities induced by the intelligent polymer droplets for propulsion of multiple objects and water cleaning through particles' capture. In perspective, the droplet can be endowed with intelligence to control the various operations by knowing a priori the exact location of the delivery and its volume.
\end{abstract}

CNR - ISASI Institute of Applied Sciences \& Intelligent Systems Viale Campi Flegrei, 34. 80078 Pozzuoli (Na), Italy

\section{Supplementary movies}

\section{Hosted file}

MOVIE S1.mp4 available at https://authorea.com/users/412387/articles/521167-intelligentpolymer-droplets-eject-membranes-and-drive-multimodal-propulsion-of-floating-objects

Movie S1: Self-Propulsion and rotation of lightweight objects floating over the water surface.

\section{Hosted file}

MOVIE S2.mp4 available at https://authorea.com/users/412387/articles/521167-intelligentpolymer-droplets-eject-membranes-and-drive-multimodal-propulsion-of-floating-objects

Movie S2: Free self-rotation of plastic grids over the water surface.

\section{Hosted file}


MOVIE S3 (1).mp4 available at https://authorea.com/users/412387/articles/521167-intelligentpolymer-droplets-eject-membranes-and-drive-multimodal-propulsion-of-floating-objects

Movie S3: Rotation of rectangular and square grids around a pivot.

Hosted file

MOVIE S4.mp4 available at https://authorea.com/users/412387/articles/521167-intelligentpolymer-droplets-eject-membranes-and-drive-multimodal-propulsion-of-floating-objects

Movie S4: Polymeric membrane formed by self-propulsion.

\section{Hosted file}

MOVIE S5.mp4 available at https://authorea.com/users/412387/articles/521167-intelligentpolymer-droplets-eject-membranes-and-drive-multimodal-propulsion-of-floating-objects

Movie S5: Propulsion of the plastic boat along a linear and circular paths.

\section{Hosted file}

MOVIE S6.mp4 available at https://authorea.com/users/412387/articles/521167-intelligentpolymer-droplets-eject-membranes-and-drive-multimodal-propulsion-of-floating-objects

Movie S6: Propulsion and formation of polymer membrane.

\section{Hosted file}

MOVIE S7.mp4 available at https://authorea.com/users/412387/articles/521167-intelligentpolymer-droplets-eject-membranes-and-drive-multimodal-propulsion-of-floating-objects

Movie S7: Propulsion and formation of the membrane by the release of intelligent polymer droplets.

\section{Hosted file}

MOVIE S8.mp4 available at https://authorea.com/users/412387/articles/521167-intelligentpolymer-droplets-eject-membranes-and-drive-multimodal-propulsion-of-floating-objects

Movie S8: Movement of the black boat analyzed by Tracker.jar software.

\section{Hosted file}

MOVIE S9.mp4 available at https://authorea.com/users/412387/articles/521167-intelligentpolymer-droplets-eject-membranes-and-drive-multimodal-propulsion-of-floating-objects

Movie S9: Propelling multiple objects, cleaning water surface and particles captured by the polymer membrane. 